\title{
El absolutismo de la realidad: un concepto problemático en la obra de Blumenberg
}

\author{
Absolutism of reality: A problematic concept \\ in Blumenberg's work
}

\author{
ELÍAS PEIRÓ LABARTA \\ Universidad de Zaragoza
}

Recibido: 02/07/14 Aceptado: 03/06/15

\section{RESUMEN}

Uno de los conceptos fundamentales de la obra de Blumenberg es de "el absolutismo de la realidad". Tanto su perspectiva antropológica como su teoría del mito toman como punto de partida este concepto para explicar aspectos como la génesis de la significatividad o el progresivo devenir histórico. Esta metáfora de reminiscencias políticas permite al pensador alemán interpretar todo rendimiento cultural como una operación de distanciamiento de este absolutismo. La meta de este artículo será llevar a cabo una revisión crítica de este concepto mostrando algunas de las inconsistencias de la argumentación desarrollada por Blumenberg.

PALABRAS CLAVE

ABSOLUTISMO DE LA REALIDAD, METAFOROLOGÍA, ANTROPOLOGÍA, MITO.

\section{ABSTRACT:}

One of the fundamental concepts of Blumenberg's work is "absolutism of reality". Both his anthropological perspective and his theory of myth take this concept as a starting point in order to explain aspects such as the origin of the significance or the progressive historical development. This metaphor of political reminiscences allows the German thinker to interpret the cultural performances as an operation of detachment from this absolutism. The goal of 
this article is to provide a critical review of this concept showing some of the inconsistencies of the arguments of Blumenberg.

KEY WORDS

ABSOLUTISM OF REALITY, METAPHOROLOGY, ANTHROPOLOGY, MYTH

\section{INTRODUCCIÓN}

UNA DE LAS EXPERIENCIAS FUNDAMENTALES DEL JOVEN BlumenBERG tuvo lugar en el cuarto de revelado fotográfico que su padre había acondicionado para dar rienda suelta a su afición. ${ }^{1}$ El futuro filósofo acompañaba a su padre en esta delicada operación con una mezcla de asombro y expectación. El tránsito entre el negativo y la imagen se producía como si de un truco de magia se tratase, como una ecuación cuyo resultado dependía del preciso manejo de sus variables: la luz y la oscuridad. A juicio de Blumenberg, este proceso ejemplificaba perfectamente la tarea del dios bíblico en lo que respecta a la creación del mundo: «Los resultados que mi padre encontraba como buenos me interesaban poco. Lo que me fascinaba era el proceso de cómo algo surgía de la nada, algo que antes no existía en absoluto. [...] uno que no cree en la creación entiende perfectamente su concepto, tal como se producía visiblemente en la cámara oscura. Desde entonces tuve al menos una idea de cómo nacen los conceptos» (2010a, 27-28).

En esta breve anécdota narrada por Blumenberg sobre su infancia aparece ya reflejado, en mi opinión, el tema fundamental sobre el que oscila su ingente producción filosófica: el problema del tránsito, del umbral, o incluso, avanzando un paso más, el de la metamorfosis. Su pensamiento no pretende desentrañar qué sea la luz o qué la oscuridad sino cómo se produce el tránsito entre ambas. Así, en el caso de sus primeras obras, como Paradigmas para una metaforología, su atención no se dirige a la metáfora sino a la transición entre ésta y el concepto. Lo mismo podemos decir de su obra Legitimidad de la Edad Moderna, en la cual la cuestión a analizar es el umbral en el que se produce el cambio del medioevo a la modernidad. Y de nuevo, en Trabajo sobre el mito, el estudio que lleva a cabo Blumemberg versa sobre la inaprehensible metamorfosis entre el mito y el logos. Metamorfosis, umbral o tránsito que tanto en éste como en los demás casos pertenece al ámbito de lo que Blumenberg denomina como lo inconceptualizable.

Pues bien, en este artículo me propongo abordar este ámbito o dimensión de lo inconceptualizable en uno de los tránsitos analizados por Blumenberg a lo largo de su obra: el paso de una realidad caótica y asignificativa al entramado

1 Cfr., «Una historia de los conceptos»(Blumenberg, 2010a, 27-28). 
cultural en el que habita el ser humano. En Trabajo sobre el mito, Blumenberg especula sobre este tránsito empleando una metáfora de reminiscencias políticas: la del absolutismo de la realidad. Cual tirano, la realidad dominaba sin concesiones ni misericordia a un ser atemorizado que para superar su angustia desarrolló una herramienta singular: la cultura. El tránsito entre ambos momentos, entre el estadio en el que el protohumano vivía expuesto a la realidad radicalmente contingente y amenazante, y el estadio en el que el ya deviene ser humano en cuanto que ser dotado y que se dota de cultura, y por tanto, ser simbólico, se muestra desde la óptica de Blumenberg como una operación de descarga elaborada sobre una infinidad de narraciones.

Pero este argumento antropológico defendido por Blumenberg, según el cual la emergencia del horizonte cultural sería un producto de la exposición del protohumano al absolutismo de la realidad, resulta problemático por dos motivos. El primero de ellos radica en que dicho absolutismo es presentado como si se tratara de una suerte de status naturalis prelingüístico, lo cual implica la incierta referencia a un afuera del lenguaje. Y derivado de esta referencia extralingüística surge el segundo aspecto cuestionable: cómo es posible que un ser no instalado en la significatividad pueda considerar la realidad como caótica o incluso absurda, y así reaccionar ante ella. Sólo desde la reflexión acerca de qué sea el orden y la seguridad -y ello ya supone pensar, razonar, conceptualizar-, se puede categorizar el absolutismo de la realidad aun cuando ésta describa una instancia inhóspita u hostil y, en último lugar, desconcertante.

Esbozadas así ya las primeras críticas, pasaré a continuación a la revisión y análisis del concepto «absolutismo de la realidad» en la obra de Blumenberg. Para ello, llevaré a cabo un triple recorrido. En la primera etapa introduciré algunos de los estudios antropológicos de su obra Descripción del ser humano. En concreto, cómo Blumenberg explica de forma genealógica el surgimiento del ser humano desde la exposición del protohumano a una situación de angustia originaria. En segundo lugar abordaré su obra Trabajo sobre el mito, donde la noción del absolutismo de la realidad adquiere un protagonismo central. Mediante el trabajo del mito y sobre el mito, el pensador de Lübeck muestra cómo se genera el mundo en tanto que horizonte simbólico -en un primer momento, va siendo estructurado por las denominaciones iniciales, y posteriormente, a través de las narraciones. Finalmente, ahondaré en las consideraciones críticas que me llevan a considerar el "absolutismo de la realidad" un concepto cuanto menos problemático.

\section{UNA APROXIMACIÓN ANTROPOLÓGICA AL PROBLEMA DEL ORIGEN}

En Descripción del ser humano, Blumenberg lleva a cabo una suerte de especulación antropológica acerca del origen de la cultura como elemento definitorio del ser humano, cuyo punto de partida es la situación del protohumano 
en un bosque originario. La principal característica de esta escena primigenia es el ajuste perfecto entre las necesidades del individuo y los medios que ofrece el entorno. El protohumano se adapta a la naturaleza de modo que todo lo que le circunda se vuelve familiar, obvio. Y esta ausencia de desfase entre «el estímulo ambiental y el desempeño orgánico» $(2011,162)$ explica el automatismo de la conducta del protohumano: un ser que pertenece sin solución de continuidad a su medio, que está disuelto en el mismo como el agua en el agua. ${ }^{2}$ A juicio de Blumenberg esta misma situación de inmersión en la cotidianidad se refleja en uno de los conceptos fundamentales de la fenomenología: el mundo de la vida. Para este pensador, el mundo de la vida es la «situación de partida antepredicativa de toda diferenciación lógica de la conciencia» $(2011,57)$, y aclara más adelante, «como el universo originario de los sobreentendidos»(2011, 59).

Pero, y retomando de nuevo la adaptación ideal entre el protohumano y su entorno, Blumenberg señala que esta situación es producto de un excedente y de la ausencia que se origina. El exceso es la obviedad. La claridad acerca de la evidencia de lo existente y de la existencia, y fruto de la cual se genera el automatismo en la respuesta, satura hasta tal punto el horizonte de los habitantes que se produce una ausencia total de asombro. Esto es, no ha lugar para la duda o la perplejidad, y ello supone la incapacidad de reflexionar. La aproximación a la salida del mundo de la vida aparece en la obra del pensador de Lübeck como una de esas transiciones de las que nada podemos saber y, sin embargo, no podemos dejar incuestionadas. Solo de forma metafórica, como en el caso del mito de la caverna platónica o en la expulsión del paraíso bíblico, podemos trazar la cartografía de esa transición, dado que, tal y como señala Blumenberg, la situación originaria no podía durar eternamente: «Lo que en este contexto se llama «mundo» puede que haya sido el momento más efímero de toda la historia de la humanidad: la inocencia de un sentirse satisfecho con lo dado, ya en peligro desde su misma entrada en la existencia, vinculada al primer miedo ante lo no dado». ${ }^{3}$ Pero ¿de dónde y cómo pudo surgir este «primer miedo»?

Blumenberg responde esta cuestión desde una óptica antropológica, situando en el tránsito del bosque originario a la sabana como el momento fundacional de la génesis del ser humano. ${ }^{4}$ Tras la salida de su «mundo de la vida»,

2 A lo largo de toda su obra, Blumenberg retrata esta situación de perfecta congruencia mediante diversas anécdotas, metáforas y mitos. En Tiempo de vida, tiempo de mundo, por ejemplo, emplea una sugestiva anécdota: nos cuenta cómo una muchacha que había vivido siempre en el mismo bosque, no podía siquiera sospechar que más allá de los límites del mismo pudiese haber algo más: «La esfera de su actividad coincidía casi por completo con su mundo, del que los ciervos y venados sabían más que ella». (Blumenberg, 2007, 49). Por ello, se pregunta el pensador alemán a continuación: «¿Cuan dilatada podrá ser la esfera del pensamiento en una cabeza así?».

3 Blumenberg, 2007, 32.

4 Esto es, para Blumenberg el ser humano surge en cuanto que el protohumano abandona 
el protohumano se ve expuesto a un horizonte caracterizado por la apertura espacial; el perfecto ajuste de antaño queda así radicalmente fracturado por una amenaza constante e imprevisible: el absolutismo de la realidad. ${ }^{5}$ Ante esta nueva situación de amenaza el ser humano experimenta por primera vez la angustia, una reacción anímica que no tenía cabida en el anterior contexto donde primaba la familiaridad. Blumenberg retoma y reelabora este concepto de la angustia introducido por Heidegger en su analítica existenciaria de Ser y Tiempo. ${ }^{6}$ En la propuesta del pensador del ser, este concepto aparece como un eslabón esencial en el proceso de evasión del Dasein de la inautencidad de la cotidianidad. Al igual que la salida de la caverna platónica, la evasión requiere un profundo compromiso personal y un esfuerzo para el que, dice Heidegger, no todos están capacitados. Inmersos en las habladurías del «se dice» y «se hace» del uno público, la mayor parte de los individuos son incapaces de escuchar la llamada de la conciencia. ${ }^{7}$ Estar a la altura del azar y aventurarse a afrontar la facticidad de la existencia se convierte así en un desafío que solo una élite espiritual está dispuesta a aceptar. Para Blumenberg, la angustia, por el contrario, lejos de ser el privilegio de aquellos que se deciden por la autenticidad, es contemplada como el mecanismo antropológico determinante por el que el ser humano deviene tal. ${ }^{8}$ Esto es, la transformación del protohumano

la protección de "una forma de vida oculta y adaptada" $(2003,12)$ y se exponerse al nuevo horizonte abierto de la sabana.

5 En Trabajo sobre el mito Blumenberg define este horizonte espacial como "un compendio de todas las direcciones de las que se puede aguardar algo indeterminado" $(2003,15)$. En esta situación, el miedo determinado deja paso a la angustia indeterminada, a la "arcaica resignación" $(2003,14)$ ante lo inconmensurable del horizonte. Y en Descripción del ser humano, señala el pensador que la angustia "paraliza el comportamiento del cuerpo porque el vacío de su horizonte implica que todo puede aparecer en cualquier momento por cada uno de sus puntos" (2011, 530).

6 Heidegger, a su vez, adoptó la noción de angustia de las obras de Kierkegaard El concepto de la angustia y La enfermedad mortal. En la primera de estas obras señaladas del pensador danés ya puede leerse, adelantando los análisis posteriores de Heidegger, "La inocencia es ignorancia. En la inocencia no está el hombre determinado como espíritu, sino sólo anímicamente determinado en unidad inmediata con su naturalidad. [...] La nada engendra la angustia. [...] es la realidad de la libertad en cuanto posibilidad frente a la posibilidad”. (Kierkegaard, 2008, 87-88).

7 En Ser y tiempo, Heidegger argumenta que las habladurías del uno público han sustituido a las cadenas y grilletes de la caverna platónica: "[...] el Dasein está sujeto al dominio de los otros en su convivir cotidiano. No es él mismo quien es; los otros le han tomado el ser. El arbitrio de los otros dispone de las posibilidades cotidianas del Dasein. [...] El quién no es éste ni aquél, no es uno mismo, ni algunos, ni la suma de todos. El "quién" es el impersonal, el "se" o el "uno". (Heidegger, 2003, 151).

8 F. Heidenreich llama la atención sobre la relación entre las categorías existenciales manejadas por Blumenberg y Heidegger. Aunque el pensamiento del primero se aleje progresivamente del pensador del ser, en su escrito de habilitación (Die ontologische Distanz : eine Untersuchung über die Krisis der Phänomenologie Husserls) se nutre de esta categoría esencial heideggeriana 
en humano tiene lugar en cuanto el protohumano logra reconducir la angustia ante la nueva situación de amenaza omnipresente e incalculable hacia una serie de miedos localizados. ${ }^{9}$ Dice Blumenberg al respecto: «La angustia ha de ser racionalizada siempre como miedo, tanto en la historia de la humanidad como en la del individuo. Cosa que no ocurre primariamente a base de experiencia y conocimiento, sino en virtud de una serie de artimañas, tales como, por ejemplo, la suposición de que hay algo familiar en lo inhóspito, de que hay explicaciones en lo inexplicable, nombres en lo innombrable» $(2003,13)$.

Así pues y sintetizando lo expuesto hasta el momento, cuando el protohumano abandona el escenario originario en el que todo estímulo se sigue de una reacción automática, se expone a la pura posibilidad del horizonte indeterminado, al absolutismo de la total contingencia. El pensador de Lübeck interpreta en este contexto la angustia como la expresión emocional de un ser que deviene consciente tanto del vacío de su libertad interior como del abismo temporal y espacial que se extiende ante sus ojos. Estas nuevas condiciones espaciales motiva lo que Blumenberg considera como la principal modificación en la génesis del ser humano: la adopción la postura erguida (cf., 2011, 106). Esta evolución funcional no solo permite emplear las manos para manipular objetos, sino también ampliar el horizonte visual. Ahora bien, Blumenberg llama la atención sobre la peligrosa ambivalencia de esta conquista evolutiva: la elevación de la postura conlleva una mayor capacidad de observación del horizonte, y en consecuencia, una mayor capacidad de anticipación a los peligros visuales, pero también conlleva una mayor exposición de uno mismo frente a los demás. De este modo, los congéneres del ser humano también pueden visibilizarlo con antelación y convertirse por tanto en peligros potenciales. ${ }^{10}$

para rearticularla en su propio discurso antropológico. Apunta Heidenreich al respecto, "In Blumenbergs Habilitationsschrift wird deutlich, wie umfangreich seine Anlehnungen an Heidegger sind: Die Konversion von Angst in Furcht durch die Konstitution von Bedeutsamkeit ist im Schlußkapitel bereits formuliert. Doch diese Fortformulierungen der Heideggerschen Existenzialanalyse können noch nicht als „Anthropologie» gelten, zumal Heidegger ja selbst diesen Titel abgelehnt und die Anthropologie als Vergegenständlichung kritisiert hat". (Heidenreich, 2005, 30).

9 En la medida en que el miedo hace referencia a un objeto circunscrito, puede ser dominado. Sin embargo, la angustia no remite a ningún ente concreto. Blumenberg, la define, de hecho, en Trabajo sobre el mito, como "una intencionalidad de la conciencia sin objeto" (2003, 12). Las primeras denominaciones serán pues el mediador entre la angustia indefinida y los miedos localizados. Así, señala en la obra citada: "El pánico y la paralización -los dos extremos del comportamiento angustioso- quedan disueltos en la apariencia de unas magnitudes de trato calculables y unas formas de trato reguladas [...]" $(2003,14)$.

10 En el capítulo "Cuerpo extraño y cuerpo propio" de Descripción del ser humano, Blumenberg desarrolla un complejo análisis sobre la tensión entre la transparencia del cuerpo propio y la opacidad del cuerpo somático. Nuestra visibilidad para los otros se muestra como la clave tanto de la intersubjetividad como de la génesis de la autoconciencia. En este sentido interpreta 
Blumenberg hace de esta capacidad para actuar a distancia uno de los conceptos centrales de su antropología (cf., 2011, 430). Para este filósofo, las ventajas de la visibilidad en el plano físico contribuyen decididamente en el desarrollo de nuevas capacidades en el plano simbólico. Así, es especialmente significativa la capacidad para anticipar los peligros que acechan al ser humano mediante la prevención. ${ }^{11} \mathrm{La}$ acción a distancia transciende por tanto el plano espacial generando un horizonte temporal: el comprendido entre el recuerdo del pasado y la anticipación del futuro. La razón se convierte entonces en el principal y esencial instrumento del nuevo equipamiento cognitivo del ser humano, puesto que no solo le permite relacionarse con lo lejano, sino también con lo inexistente. La razón se muestra, señala el pensador de Lübeck, como la actio per distans genuina: «La razón es la capacidad de obtener enunciados sobre todo lo que no sólo no está presente fácticamente y no es intuible, sino que no es real en absoluto, sino sólo posible o incluso imposible» (Blumenberg, 2010b, 449). Mediante este nuevo operador simbólico, el ser humano deja de habitar exclusivamente en el mundo de lo fáctico para hacerlo también en el mundo de lo no presente, este es, el horizonte del pensamiento. Inmerso en este horizonte, el ser humano trasciende el automatismo para instalarse en los márgenes oscilantes de la dilación y el titubeo, la prevención frente a la reacción inmediata o la planificación frente a la huida. La fractura abierta entre el principio de deseo y el principio de realidad tras la expulsión del bosque originario queda por tanto suturada mediante está nueva capacidad simbólica. Una capacidad de la que dependerá la construcción del nuevo paraíso cultural poblado de denominaciones y narraciones míticas en el que pasa a habitar el ser humano.

\section{UNA APROXIMACIÓN MITOLÓGICA AL PROBLEMA DEL ORIGEN}

En Trabajo sobre el mito, Blumenberg hace depender la apertura de este paraíso cultural de una operación de distanciamiento. El absolutismo de la realidad queda despotenciado según el ser humano cubre su amenaza mediante

\footnotetext{
Blumenberg el relato bíblico de la caída del paraíso, como una metáfora absoluta de la primera exposición a la visibilidad: "El instante mítico en el que el padre de la humanidad fracasa en su intento de ocultarse refleja el shock de la experiencia prehistórica del protohumano empujado de la selva protectora al campo libre [...] El shock de la visibilidad está en el humano desde su historia como la conciencia de una ser vivo con mucha espalda" $(2011,589)$. Las ventajas de la autoconciencia y la intersubjetividad son por tanto directamente proporcionales a una nueva vulnerabilidad del ser humano. Uno de los rendimientos del entramado cultural es precisamente compensar esta vulnerabilidad, ofrecer "la posibilidad de transformar el arriesgado poder ser visto en el calculado mostrarse y el lúdico exhibirse [...]" $(2011,109)$.

11 A juicio de Blumenberg, para el ser humano "anticiparse lo es todo" $(2011,443)$, debe "dominar las situaciones críticas antes de que se produzcan" $(2011,443)$.
} 
un velo tejido por las primeras denominaciones. En la medida en que lo absolutamente otro es expresado en entidades nominales, la angustia indefinida puede ser localizada en una serie de instancias conocidas, de modo que todo lo que anteriormente se mostraba inaccesible, ahora se introduce en la esfera de la familiaridad. ${ }^{12}$ Toda alteridad queda por tanto reconducida a una matriz significativa, a un entramado de poderes y contrapoderes. Esto es, lo otro queda introducido en una estructura dialógica que permite al ser humano relacionarse con las potencias naturales. Y sólo tras este reconocimiento dialógico podrán implorarse favores y condenas, dar sentido a los desastres naturales o a los golpes de fortuna (cf., 2003, 20). Los acontecimientos no deseados se interpretan entonces como el resultado de las desavenencias entre los humanos y los dioses. De esta forma, en cuanto que éstos actúan como agentes de los sucesos anteriormente inexplicables, la arbitrariedad se reconduce al plano significativo. En efecto, mientras los dioses sean temidos, adorados o burlados, la indiferencia de la realidad respecto al ser humano queda sublimada y cubierta con el espesor de las tradiciones. Los dioses aparecen así como los elementos constructivos de las interminables narraciones sobre el origen del mundo, sus patrones repetitivos y sus acontecimientos inesperados. ${ }^{13}$

Esta aproximación de Blumenberg a la génesis del mundo en tanto que horizonte significativo contiene una serie de ingredientes que nos permiten situarla en la constelación teórica del funcionalismo, y en concreto, en la estela de autores como el antropólogo Malinowski, o los sociólogos Durkheim

12 Dice Blumenberg que la instalación nominativa permite "conducir la indeterminación de lo ominoso a una concreción de nombres", "hacer de lo inhóspito e inquietante algo que nos sea familiar y accesible" $(2003,33)$. Así, empapado por las narraciones míticas, el mundo se transforma en un horizonte de sentido bajo el que queda sepultado el absurdo anterior. Lo indeterminado adquiere un rostro y una denominación, y de esta forma, lo distante se nos torna cercano. Apunta Blumenberg en Trabajo sobre el mito, "Toda confianza en el mundo comienza con los nombres de los cuales se pueden narrar historias [...] la denominación certera de las cosas superará la enemistad entre ellas y el hombre, que se convertirá en una relación de servicialidad" $(2003,42)$.

13 A juicio de Blumenberg, el ingrediente fundamental del mito es el politeísmo, el reparto de los poderes que amenazan al ser humano entre varios dioses: "En su empeño de desmontar el absolutismo de la realidad hizo [el ser humano], a partir de un informe bloque de poderío opaco -que estaba sobre el hombre y contra el hombre-, un reparto en multitud de poderes que competían entre sí y hasta se invalidaban mutuamente" (Blumenberg, 2003, 21). El politeísmo permite no solo dividir el absolutismo de la realidad en una serie de poderes reconocibles, sino que, a su vez, promueve que estos poderes se vean acotados correlativamente. El absolutismo de un Dios único queda imposibilitado en un sistema basado en competencias regionales y limitaciones recíprocas. [Odo Marquard obtendrá de esta tesis una serie de conclusiones extrapolables al ámbito político. Vid. Marquard, "Lob des Polytheismus: über Monomythie und Polymythie" en Abschied vom Prinzipiellen, Reclam, 1981, 91-116.] 
y R. K. Merton. ${ }^{14}$ El punto de partida de todos ellos a la hora de aproximarse al estudio de los mitos y rituales es la diferenciación entre la función latente y la función manifiesta. Así, por ejemplo, Merton se refiere a la danza de los Hopi, que aparentemente pretende desencadenar la llegada de la lluvia (función manifiesta) pero que en realidad procura mejorar la cohesión social del grupo (función latente). ${ }^{15}$ La explicación funcionalista de Merton permite comprender el hecho de que sobrevivan prácticas que no resultan eficientes en su función manifiesta. Si retornamos al análisis de Blumenberg, observamos que su explicación acerca de la supervivencia de los mitos se sitúa en este mismo paradigma. Su tesis radica en que más allá de la función manifiesta de las diferentes historias, la función latente de las mismas no es otra sino distanciar al ser humano del absolutismo de la realidad. Un absolutismo que el mito no puede «decir» sino en todo caso «mostrar», ya que el absolutismo de la realidad no es un acontecimiento objetivo sino una suerte de concepto límite. ${ }^{16}$

Esta tesis de Blumenberg vertebra de forma transversal las diferentes dimensiones de su aproximación al trabajo del mito. Una muestra de ello la encontramos en su análisis del esquema politeísta en el que se apoyan las narraciones míticas. A juicio del Metaforólogo, el mito convierte el «informe bloque de poderío opaco» en «un reparto en multitud de poderes que competían entre si y hasta se invalidaban mutuamente» $(2003,21)$. Como hemos visto anteriormente, el tránsito del bosque originario a la sabana supuso para el homínido la exposición a una situación de continua amenaza. La angustia ante el peligro indefinido se calmó en cuanto que éste se dividió en miedos regionales. Aquí entró en juego el surgimiento de las diferentes divinidades: a cada una de ellas se le asignó el poder caprichoso sobre una parcela de la realidad -una realidad originariamente indivisa e incontrolable. Así, se pasó de una amenaza ilimitada del terror ante lo absolutamente desconocido a su división y transformación en una multiplicidad de peligros acotados. Frente a la función manifiesta, aparente, de sus variadas narraciones, éste será pues el significado latente del politeísmo: atreverse a desafiar el absolutismo de la realidad.

14 De hecho, J. Davenport no sólo señala esta afinidad sino que considera la teoría del mito de Blumenberg como una propuesta funcionalista. (cf. Davenport 1997, 23).

15 Cfr., Merton, 1992, 74.

16 Para H. Wismann, el pensamiento de Blumenberg se caracteriza por su renuncia a la cosa en sí. El ser humano construye su mundo de forma inmanente, al igual que un molusco va construyendo su caparazón mediante sus propias secreciones. Ahora bien, el mundo humano trasciende el plano físico para convertirse en un horizonte simbólico. (Wismann, 2010, 92). Ahora bien, como veremos más adelante el supuesto de Wismann resulta cuestionable. A pesar de que Blumenberg hace del absolutismo de la realidad una suerte de concepto límite, su argumentación tiende a objetivarlo como si de un en-sí extralingüístico se tratase. 
Así pues, para Blumenberg, el trabajo del mito consiste en cubrir el absolutismo de la realidad con las narraciones. El trabajo sobre el mito, por el contrario, se basa en hacer que el trabajo del mito sea invisibilizado. ${ }^{17} \mathrm{Blu}-$ menberg parece haberse inspirado en el psicoanálisis freudiano a la hora de desarrollar estos conceptos, pues la labor del «trabajo del mito» se muestra como una extrapolación del trabajo onírico. Veamos: mientras soñamos, el subconsciente elabora el material diurno organizando narraciones estructuradas por la dinámica de los deseos; una vez que despertamos, no recordamos prácticamente nada de lo soñado, y en caso de recordar algo, se nos aparece como una quimera nocturna. En el mismo sentido, los mitos elaboran el material diurno de una realidad difícilmente soportable. Sus narraciones son una suerte de sueño racional que en los albores de la humanidad permitieron al ser humano protegerse de la falta de sentido de una realidad amenazante. Cuando el logos despierta, el mito se reduce a un mero elemento literario, cumpliendo así su genuina finalidad, que no es otra que la de hacer olvidar su trabajo previo sobre del absolutismo de la realidad.

A juicio de Blumenberg, la característica principal de las narraciones míticas es su plasticidad: el cambiante horizonte de expectativas del público receptor modula su morfología haciendo de mitos, fábulas y metáforas un barómetro sensible a sus modificaciones. La metaforología de Blumenberg se desarrolla como una suerte de arqueología del discurso, como un estudio atento a las mutaciones en los diferentes estratos del mismo. Ahora bien, se trata en todo caso, de una arqueología que lejos de buscar una suerte de mito originario se limita a estudiar las huellas impresas en la transvaloración de los mismos. Por ello, cada nueva interpretación no es ninguna deformación del material originario; antes bien, se trata de la única forma en la que éste llega a cumplir

17 El mito calla sobre el absolutismo de la realidad, que es sublimado en el fondo de lo no pensable. El trabajo sobre el mito contribuye a que se silencie el terror originario. En este sentido juega R. Bodei con la etimología del término "mythos": "Le terme mythos a la même racine que la latin mutus, en quoi «mythe» indique un récit qui ne fait pas que " parler », mais qui, dans le même temps, se tait. Le mythe contient en soi une alchimie du dicible et de l'indicible, en tant qu'il représente l'articulation des deux, le dit qui renvoie au fond tacite du non-dit. Nous partons toujours de l'ineffable, de ce qui tient effectivement á cœur, mais que nous ne sommes pas en mesure d'exprimer de manière achevée, dans une forme définitive" (Bodei, 2004, 215). En el núcleo del mito permanece oculta esa referencia a lo indecible. En términos psicoanalíticos, podríamos hablar de una suerte de represión, de un olvido latente que actúa borrando el recuerdo de un sinsentido originario: el absolutismo de la realidad queda sublimado bajo las capas significativas del mito. Así, la fundación de sentido (el trabajo del mito) es ocultada tras la reelaboración narrativa de sus historias (el trabajo sobre el mito). Y así, el ser humano queda protegido de la decepción que supone habitar una realidad carente de sentido. Siguiendo esta línea argumental, se puede afirmar que el momento fundacional de la cultura fue el momento de la gran represión: el olvido del absolutismo de la realidad. 
su cometido: «El mito siempre se ha trasvasado a su recepción y permanece en ella [...] únicamente se nos presenta en la modalidad de su propia recepción, no existe ningún privilegio a favor de determinadas versiones, presuntamente más originarias o definitivas». ${ }^{18}$

La plasticidad del mito no es en cualquier caso total, sino que a lo largo del proceso de recepción van quedando coaguladas una serie de constantes icónicas resistentes a las oscilaciones del sentido histórico (cf., 2003, 41). Para Blumenberg, la función desempeñada por estas constantes es reocupada progresivamente haciendo del devenir histórico un proceso articulado por el intercambio de papeles. ${ }^{19}$ La historia de las ideas se despliega bajo la presión evolutiva de la recepción sobre estos núcleos funcionales cuya tarea descansa en última instancia en llevar a cabo la deconstrucción del absolutismo de la realidad.

Si retomamos de nuevo la distinción entre función manifiesta y función latente, el trabajo sobre el mito sería la función manifiesta y el trabajo del mito la función latente. Sobre esta distinción se articula tanto la filosofía de la cultura de Blumenberg en general, como su debate con los teóricos de la secularización en particular. Si lo único originario es la distancia respecto a todo origen, lo único «sustancial» en estas constantes icónicas será su trabajo de deconstrucción del absolutismo de la realidad. En el núcleo de toda narración descansa pues la función latente del mito. Desde este punto de vista, todo contenido cultural desempeña en definitiva el mismo trabajo: contribuir a dar sentido al mundo despotenciando su absolutismo. Incluso la actitud teórica, asociada a la racionalidad, tiene la misma finalidad que el mito: convertir lo extraño en familiar y contribuir a dotar al mundo de significados y valores. En consecuencia, la diferencia cualitativa entre mito y logos se reconduce a una continuidad narrativa. Al igual que en el caso de los mitologemas fundamentales, las teorías supervivientes son los núcleos icónicos mejor adaptados en el proceso evolutivo de las ideas. ${ }^{20}$

18 Blumenberg 2003, 295.

19 Este argumento cobra relevancia en cuanto a la polémica que establece Blumenberg con los teóricos de la secularización. Esta es: en La Legitimidad de la Edad Moderna, Blumenberg argumenta que la modernidad, lejos de ser una continuación del medievo con otros medios (tesis defendida por Karl Löwith o Carl Schmitt entre otros autores), es una época genuina. La continuidad entre ambas épocas no es por tanto sustancial, sino funcional: ambas quedan imbricadas por un complejo proceso de recambio de papeles.

20 La clave de la filosofía de la cultura de Blumenberg descansa en última instancia de su concepción del ser humano como Mängelwesen. Blumenberg retoma este concepto de la antropología de Gehlen para mostrar al ser humano como un ser deficitario, como la "improbabilidad en carne y hueso", como "el animal que a pesar de todo vive" $(2011,411)$. A juicio del pensador de Lübeck la pregunta antropológica fundamental no es tanto qué es el ser humano sino más 


\section{UNA APROXIMACIÓN CRÍTICA A LA PROPUESTA DE BLUMENBERG}

La perspectiva de Blumenberg sobre el origen del horizonte de sentido del mundo se asienta sobre una ambivalencia problemática. Coherente con el paradigma del giro lingüístico, Blumenberg evita en su argumentación toda referencia a un afuera del lenguaje: el trabajo del mito no es considerado como el rendimiento de un sujeto activo sino como algo con lo que el ser humano se encuentra siempre ya (cf., 2003, 15, 73). La significatividad del mundo es, por tanto, el producto de un proceso anónimo, de una decantación temporal ajena a toda síntesis activa (cf., 2003, 79). Toda producción simbólica posterior se edifica sobre los cimientos sedimentados en el trabajo del mito. Pero, a su vez, la argumentación de Blumenberg pretende reforzar la dimensión activa y productiva del ser humano en lo que a su devenir histórico se refiere. Frente a las propuestas que hacen de la historia del ser humano un destino sellado, Blumenberg insiste en la libre determinación del acontecer histórico.

La toma de distancia respecto al absolutismo de la realidad se convierte en el ingrediente esencial de la filosofía de la historia del pensador alemán. Éste es el mecanismo fundamental del movimiento dinámico de un ser esencialmente inadaptado y obligado de forma continua a establecer mediaciones con una realidad en la que nunca acaba de estar en casa. Retornemos a la argumentación desarrollada por Blumenberg en Trabajo sobre el mito para centrar de nuevo nuestra atención sobre ese estado primordial en el que el protohumano se enfrenta a un mundo carente de significado y familiaridad. En el discurso de Blumenberg, la angustia ante esta realidad innominada es el desencadenante de la evolución del protohumano hasta su dimensión simbólica. El absolutismo de la realidad es el de lo absolutamente otro, el de una potencia totalmente heterogénea, prácticamente trascendental. Esto es, Blumenberg describe el absolutismo de la realidad como la fuente originaria del terror y del absurdo, como aquello que estimula a la producción de una mismidad simbólica. Ahora bien, este presupuesto resulta cuestionable por el siguiente motivo: toda aprehensión de un contexto en tanto que absurdo o no significativo depende de la instalación en un horizonte de sentido desde el que llevar a cabo esta distinción. En el pensamiento de Heidegger encontramos una herramienta hermenéutica que permite aclarar la posible contradicción de la propuesta de Blumenberg: la noción de «anticipación de sentido». Como señala Heidegger, la consideración de algo como carente de sentido depende de una anticipación del mismo, para

bien cómo es posible que un ser con estas características pueda sobrevivir. Todo rendimiento simbólico, ya sea fruto del "mito" o del "logos" es interpretado por Blumenberg como una suerte de "programa de emergencia" $(2011,412)$, de compensación de la pobreza instintiva del ser humano y de su inadaptación biológica. 
lo cual es necesario una instalación previa en el mundo. ${ }^{21}$ Solo formando parte de un universo compartido de significados, puede aparecer algo como no significativo, amenazante y absolutista. La percepción del absurdo se convierte, por tanto, en un rendimiento secundario del estar arrojado en el mundo. ${ }^{22}$

Así pues, el magma caótico, innominado y absolutamente amenazante al que, según Blumenberg, se enfrenta el protohumano resulta poco plausible si compartimos las tesis de Heidegger. El protohumano únicamente puede percibir el caos desde su instalación en un orden, en un contexto significativo. Por lo tanto, el caos, el absurdo y lo informe, descritos por el pensador de Lübeck como elementos ajenos a la esfera de sentido del mito, deberían ser integrados como componentes del mismo, como elementos indispensables en su sistema de categorías correlativas. En la medida en que Blumenberg no lleva a cabo esta integración, pretende dar cuenta de la significatividad desde fuera de la misma.

En la misma línea que Heidegger, Gadamer hace hincapié sobre la dependencia del ser humano de la anticipación de sentido a la que pertenece. No podemos hablar de un afuera del lenguaje pues el ser humano esta siempre ya inscrito en su horizonte significativo desde el que se declina todo proyecto de comprensión. Como señala el pensador de Marburgo en su obra Verdad y Método, el individuo pertenece íntimamente al movimiento de la historia: "En realidad no es la historia la que nos pertenece, sino que somos nosotros los que pertenecemos a ella. [...] La autorreflexión del individuo no es más que una chispa en la corriente cerrada de la vida histórica. Por eso los prejuicios del individuo son, mucho más que sus juicios, la realidad histórica de su ser"(2007, 344). Ciertamente, el planteamiento metaforológico de Blumenberg no es incompatible con estas consideraciones de la ontología hermenéutica. Blumenberg también considera los prejuicios como la realidad histórica de cada individuo. Esos prejuicios son el producto de un ser con mucha espalda pero que también

21 La noción de "anticipación de sentido" se encuentra Ser y tiempo, la obra central del pensamiento de Heidegger. Para que un ente intramundano pueda ser reconocido en tanto que tal, el Dasein debe estar inmerso en la significatividad de un horizonte simbólico. En palabras de Heidegger: "El ente intramundano en general es proyectado hacia un mundo, es decir, hacia un todo de significatividad a cuyos respectos remisionales la ocupación, en cuanto estar-en-elmundo, se ha ligado de antemano. Cuando un ente intramundano ha sido descubierto por medio del ser del Dasein, es decir, cuando ha venido a la comprensión, decimos que tiene sentido" (Heidegger, 2003, 175).

22 J. Davenport llama la atención sobre esta contradicción en la argumentación de Blumenberg recurriendo a las categorías desarrolladas por Heidegger. En su opinión, el pensamiento de Blumenberg genera una asimetría insostenible entre un status naturalis extralingüístico y un mundo significativo generado como reacción frente al primero: "[...] only because it is encountered by Dasein in its transcendence can what in present-at-hand even appear as "unmeaning" and absurd. From this point of view, Blumenberg's asymmetry between transcendence and the absolutism of reality would become untenable." (Davenport, 1997, 48). 
posee un margen de acción inalienable, este es, aquel espacio ganado mediante su capacidad para actuar a distancia: un espacio cuyos márgenes van oscilando en función de las diferentes operaciones de descarga del absolutismo de la realidad que van sucediéndose a lo largo del devenir histórico. Este margen de acción tiende a quedar anulado en propuestas como la de Heidegger y la de Gadamer al hacer del ser humano un elemento encadenado férreamente al movimiento de la historia. De este modo, la propia historia se configura como una nueva potencia absolutista, como una narración desplegada autónomamente en la que el ser humano no es más que un personaje de una trama decidida de antemano. ${ }^{23}$ La presencia latente del absolutismo de la realidad permite a Blumenberg escapar a este determinismo haciendo del ser humano participe activo de la deconstrucción histórica de lo innombrable. Cada época ha de lidiar con este fondo irreductible que generación tras generación obliga al ser humano a enfrentarse a aquello que no cabe encerrar de forma definitiva bajo los límites del concepto.

La aproximación llevada a cabo por Blumenberg respecto al absolutismo de la realidad es ciertamente una empresa arriesgada. Al igual que el aforismo de la mosca encerrada en la botella de cristal, descrito por Wittgenstein en sus Investigaciones filosóficas, Blumenberg arremete contra los límites del lenguaje para hablar de lo que debería permanecer en el silencio. La especulación acerca del absolutismo de la realidad aparece como una de esas contusiones que el pensamiento se produce al no conformarse con los límites impuestos. Ahora bien, conforme a las tesis de Blumenberg, esta es precisamente la tarea asignada a los mitos, metáforas y demás narraciones que nos guían hacia la inconceptuabilidad: generar un espacio para pensar lo impensable, aquello que escapa a los límites del concepto pero que no por ello ha de condenarnos al silencio y la pasividad.

\section{REFERENCIAS BIBLIOGRÁFICAS}

BLUMENBERG, H., 2003: Trabajo sobre el mito. Trad. P. Madrigal. Barcelona: Paidós.

_,2004: Salidas de la caverna. Trad. J. L. Arántegui. Madrid: Antonio Machado Libros.

___ 2007: Tiempo de la vida y tiempo del mundo. Trad. M. Canet, Valencia

23 Blumenberg se muestra en este sentido como un crítico mordaz de la propuesta heideggeriana de la historia del ser. A juicio de Blumenberg, esta propuesta se configura como una suerte de recidiva gnóstica en la medida en que hace depender el destino del ser humano de una potencia inapelable y de corte trascendental. El olvido del ser se convierte así en el determinante fundamental de una historia de la metafísica basada en la degeneración tanto de la relación del ser humano con el mundo como consigo mismo. 
: Pretextos.

___ 2008: La legitimación de la Edad Moderna. Trad. P. Madrigal. Valencia: Pre-textos.

____ 2009: La risa de la muchacha tracia. Una protohistoria de la teoría. Trad. T. Rocha e I. Reguera. Valencia: Pre-textos.

___ 2010a: Conceptos en historias. Trad. C. G. Cantón. Madrid: Editorial Síntesis.

___ 2010b: Descripción del ser humano. Trad. G. Mársico. Buenos Aires: Fondo de Cultura Económica.

BODEI, R., 2004: "Navigatio vitae. Métaphore el concept dans l'œuvre de Hans Blumenberg", en Archives de philosophie, 67, cahier 2.

DAVENPORT, J., 1997: Blumenberg, Heidegger, and the Origin of Mythology. A Critique of 'Invisible Hand' Models in Historical Explanation. Consultado en http://faculty.fordham.edu/davenport/texts/Blumenberg-web.pdf

____ 2010: «Entretien avec Heinz Wismann» en Cahiers philosophiques, 123/trimestre, pp. 89-100.

GADAMER, H.G., 2010 : Verdad y Método. Salamanca: Ediciones Sígueme. HEIDEGGER, M., 2003: Ser y Tiempo. Trad. J. E. Rivera. Madrid: Trotta.

HEIDENREICH, F., 2005: Mensch und Moderne bei Hans Blumenberg. München: Wilhem Fink Verlag.

HÜBENER, W., 1983: "Carl Schmitt und Hans Blumenberg, oder über Kette und Schluss in der historischen Textur de Moderne", en J. Taubes, Religionstheorie und politische Theologie. Der Fürst dieser Welt. München: Fink/ Schöningh, p. 57-76.

KIERKEGAARD, S. 2008: El concepto de la angustia. Trad. D. Gutiérrez Rivero. Madrid: Alianza.

LAFONT, C., 1997: El lenguaje y apertura del mundo. El giro lingüístico de la hermenéutica de Heidegger. Madrid: Alianza.

MERTON, R. 1992: Teorías y estructuras sociales. México: Fondo de Cultura Económica.

RUSCH, P., 2010: "Hans Blumenberg et la grammaire historique des idées" en D. Treirweiler (Coord.), Hans Blumenberg. Anthropologie philosophique. Paris: PUF, pp. 141-163.

WETZ, F. J., 2009: “The Phenomenological Anthropology of Hans Blumenberg”, en Iris, I, 2, pp. 389-414. 
Elías Peiró Labarta es Becario FPU en la Universidad de Zaragoza.

Líneas de investigación:

Filosofía contemporánea. Hermenéutica y fenomenología

\section{Publicaciones:}

Peiró, E.: «Transiciones metafóricas en la representación de la realidad. Reflexiones a partir de la obra de Hans Blumenberg», en Thémata. Revista de filosofía, 47 (2013) pp.: 219-240.

Correo electrónico: epeirolabarta@hotmail.com 